\title{
Assessing plant water status from infrared thermography for irrigation management
}

\author{
by M. Zovko*, I. Boras** and S. Švaićc* \\ * Univ. of Zagreb Faculty of Agriculture, 25, Svetošimunska cesta, Zagreb, Croatia, mzovko@agr.hr \\ ** Univ. of Zagreb Faculty of Mechanical Engineering and Naval Architecture, 5, Ivana Lučića, Zagreb, Croatia, \\ iboras@ncbr.gov.pl
}

\begin{abstract}
Research was conducted in the vineyard grown in artificially transformed karst terrain (Croatia). The experimental design included four irrigation treatments in three replicates. Temperature measurements were carried out using an infrared thermal imaging camera. Biological properties, such as the leaf water potential (LWP) were also measured. The obtained crop water stress index (CWSI) values and the measured LWP values were used to create multiple regression models. It was concluded that if an automatic thermal imaging method which produced thermal images of sufficiently high quality is used, then the automatic method for the calculation of CWSI developed here is confidently applicable.
\end{abstract}

\section{Introduction}

In many parts of the Mediterranean karst surfaces have been directly modified by stone crushing to create a larger and flatter area for cultivation, mostly for grapevine and olive production. After the deforestation, new grapevine and olive trees plantations are made particularly on the slopes exposed to the sun and sheltered from strong winds.

The karst areas along Croatian coast benefits from Mediterranean climate with worm to hot, dry summers, and frequent winds, conditions that favour organic vineyard management. Average annual precipitation of the area ranges from $557 \mathrm{~mm}$ to $1200 \mathrm{~mm}$ being quite evenly distributed over the year, and the driest from May to September. In stony and gravelly soils rain water percolates rapidly downward through the soil layers. Moreover, excessively dry topsoils can cause water run-off and thus significant evaporative loss of water. Thus, the lack of moisture can be an important risk indicator in vine production within these areas [1].

Karst freshwater constitutes by far the main source of drinking water and its use for irrigation is particularly unsustainable. According to United Nations estimates by 2050 two-thirds of the world's population will be living in waterstressed conditions. The rational use of water for irrigation plays an important role in managing vineyard within karst landscape. In this perspective it becomes essential to improve water management within existing cropping systems through the development of new irrigation management strategies.

Vine phenology and grape ripening are highly dependent on water uptake conditions. It is known that mild water deficit stress can enhances grape quality (including increase berry sugar content), especially in red cultivars [2]. Aiming at cost minimization, practical grapevine production prefers relying on a small set of inexpensive and simple tools/methods enabling combined measurement of soil- and plant-based water status [3]. This commonly involves measuring relative water content of the root-zone as an estimate of the soil-water supply (balance).

Soil-based irrigation scheduling techniques enable for calculation of amount of water, which needs to be supplied in order to compensate for given soil-water deficit. However, water measuring in of the root-zone of the skeletal karst soils is especially challenging because: 1) the very coarse nature can pose soil contact problems for some of the available soil moisture monitoring devices [4]; 2) soils which are made by rock ploughing show great within-filed variability (e.g. the proportion of gravel can range from 40 to more than $70 \%$ ) and significantly more probes are required for accurate assessment of soil-water content.

Plant-based water demand is commonly assessed by measuring leaf or stem water potential. Leaf water potential (LWP) is often preferred due to its integrative nature enabling minimal set of measurement locations, and due to availability of measurement tools (pressure chambers [5]. Though, the LWP measurement is long lasting procedure and for good results the samples must be taken from various points in the field it is not very practice. Previous research showed that canopy temperature can be a robust indicator of grapevine water status/water stress condition. Quantitative thermography opens the possibility of fast and non-destructive spatio-temporal monitoring of water stress detection in plants using leaf temperature. Thermal imaging data, gained from aerial photographs of a crop with a digital thermal camera, has proved valuable in irrigation scheduling, increasing water use efficiency [6]. This gives the opportunity to quantitative thermography to be used to estimate grapevine water status.

The main objective of this research was to explore the digital thermography for determining water status in vine plants (Vitis vinifera L) grown on stony soil. 


\section{Materials and methods}

\subsection{Study site and experimental design}

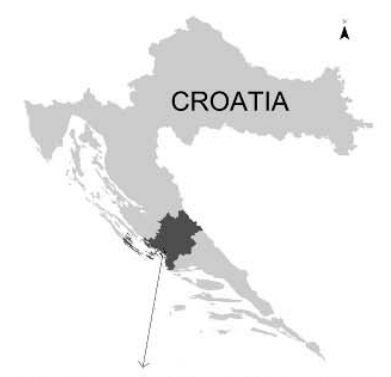

DONJE POLJE - JADRTOVAC

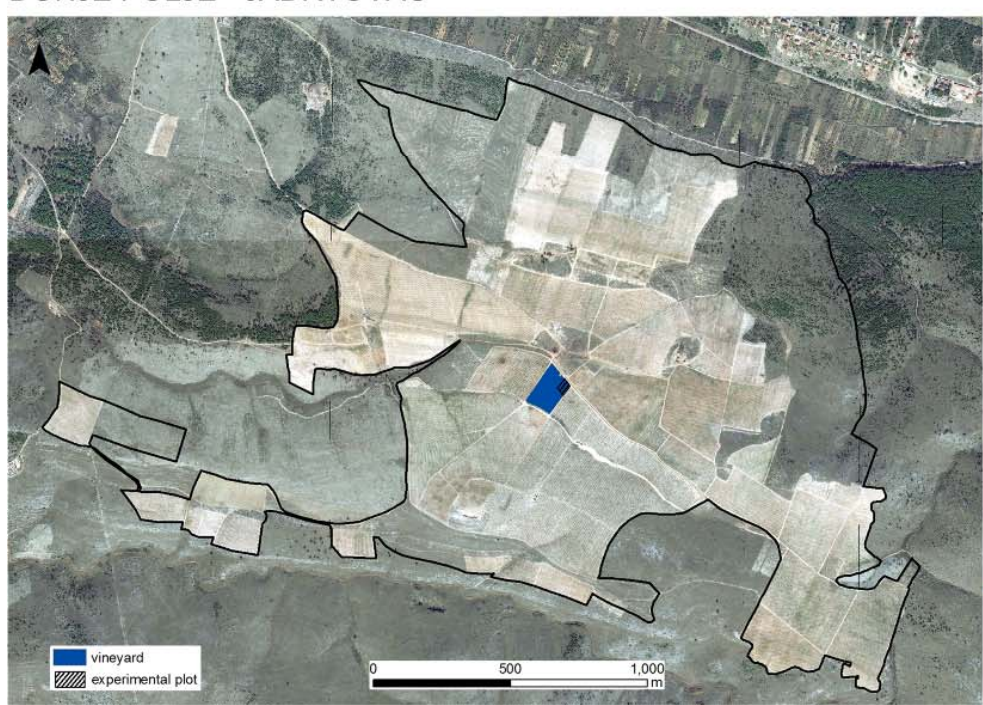

SCHEME OF EXPERIMENTS

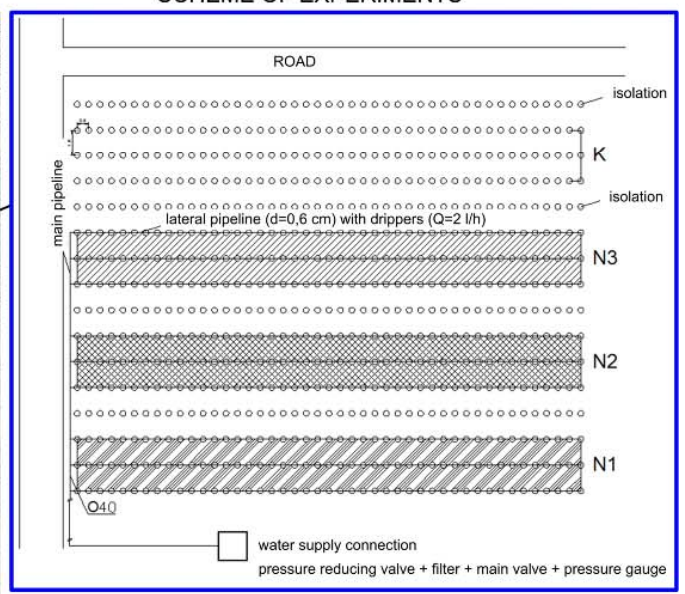

Fig. 1. Aerial photograph of the study area and the maps of the vineyard plot with respective treatments (Zovko et al., 2017)

The irrigation experiment was conducted over four consecutive years (2014-2017) at a commercial organically managed vineyard (Vitis vinifera L.) of 7- year old "Babic" vines $(0.8 \times 2.0 \mathrm{~m}$ spacing) located in Šibensko kninska county in the wine producing region of Croatia with Mediterranean climate (figure 1). Vines were grafted on Richter 110 rootstock and trained to a vertically shoot-positioned trellis system. At the site under consideration, the soil, remediated by stone crushing, is fairly shallow $(<0.5 \mathrm{~m}$ ), containing up to $94 \%$ (by weight) of soil particles larger than $2 \mathrm{~mm}$ and up to $78 \%$ (by weight) of rock fragments larger than $25 \mathrm{~mm}$ [1].

Irrigation scheduling was based on estimated crop evapotranspiration (ETc) so the amount of added water was equal to total crop evapotranspiration losses. A meteorological station (Complete Weather Station - DACOM, Netherlands) was installed on the experimental plot to measure precipitation, temperature, relative air moisture, wind speed and direction, solar radiation and leaf moisture. The station had an additional application for reference evapotranspiration (ETo). Four irrigation treatments were applied in the vineyard: 1) control - non-irrigated (K); 2) irrigated at $100 \%$ ETc (N3), 3) irrigated at $75 \%$ ETc (N2) and 4) irrigated at $50 \%$ ETc (N1) from mid-June to mid-August. Each treatment contained 3 lines (replicates) of grapevines (figure 1). Irrigation water was supplied through a drip irrigation system with one $2 \mathrm{l} / \mathrm{h}$ dripper per vine positioned at regular intervals along the one pipe for treatment N1, two pipes for treatment $\mathrm{N} 2$ and three pipes for treatment N3.

\subsection{Thermal imaging}

Nine grapevines were selected randomly per irrigation regime (three grapevines within each experimental) for thermal imaging and measurements. Lateral thermal images of vines were taken with a thermal camera Ti25 FLUKE. Thermal characteristic of the camera was: temperature measurement ranges from $-20{ }^{\circ} \mathrm{C}$ to $+350{ }^{\circ} \mathrm{C}$; temperature measurement accuracy: $\pm 2{ }^{\circ} \mathrm{C}$ or $2 \%$; detector type: $160 \times 120$ Focal Plane Array, uncooled microbolometer; spatial resolution (IFOV): 2,5 mRad. All images were analysed with Software: SmartView ${ }^{\circledR}$. The measurements have been done from distances of about $1 \mathrm{~m}$ (fig.2). Emissivity factor for leaves was 0,96. Images were taken 27 July 2017 from 9 am to $11 \mathrm{am}$. 


\subsection{Grapevines leaf water potential measurements}

Leaf water potential (LWP) was measured using pressure chamber (Plant water status console, Soilmoisture Equipment Corporation, USA) on one leaf (sun-exposed fully mature) per selected grapevine, on nine grapevines per irrigation regime. LWP was used as referent field-technique (destructive) of water potential estimation (measurement of grapevine's water demand/status (table 1).

Table 1. Reference values of grapevines's leaf water potential and grapevine water status

\begin{tabular}{|l|l|}
\hline & Middy LWP(MPa) \\
\hline No water deficit & $>-0,9$ \\
\hline Weak water deficit & $-0,9$ to $-1,1$ \\
\hline Moderate to weak water deficit & $-1,1$ to $-1,3$ \\
\hline Moderate to severe water deficit & $-1,3$ to $-1,4$ \\
\hline Severe water deficit & $<-1,4$ \\
\hline
\end{tabular}

\section{Results and discussion}

The grapevines were irrigated over the period from mid-June to mid-August 2017, typically once every two days. Average air temperature 27 July 2017 (thermal images were taken) was $24.1^{\circ} \mathrm{C}$ and daily maximum temperature was $31.1^{\circ} \mathrm{C}$, without precipitation and average air moisture of $61 \%$.
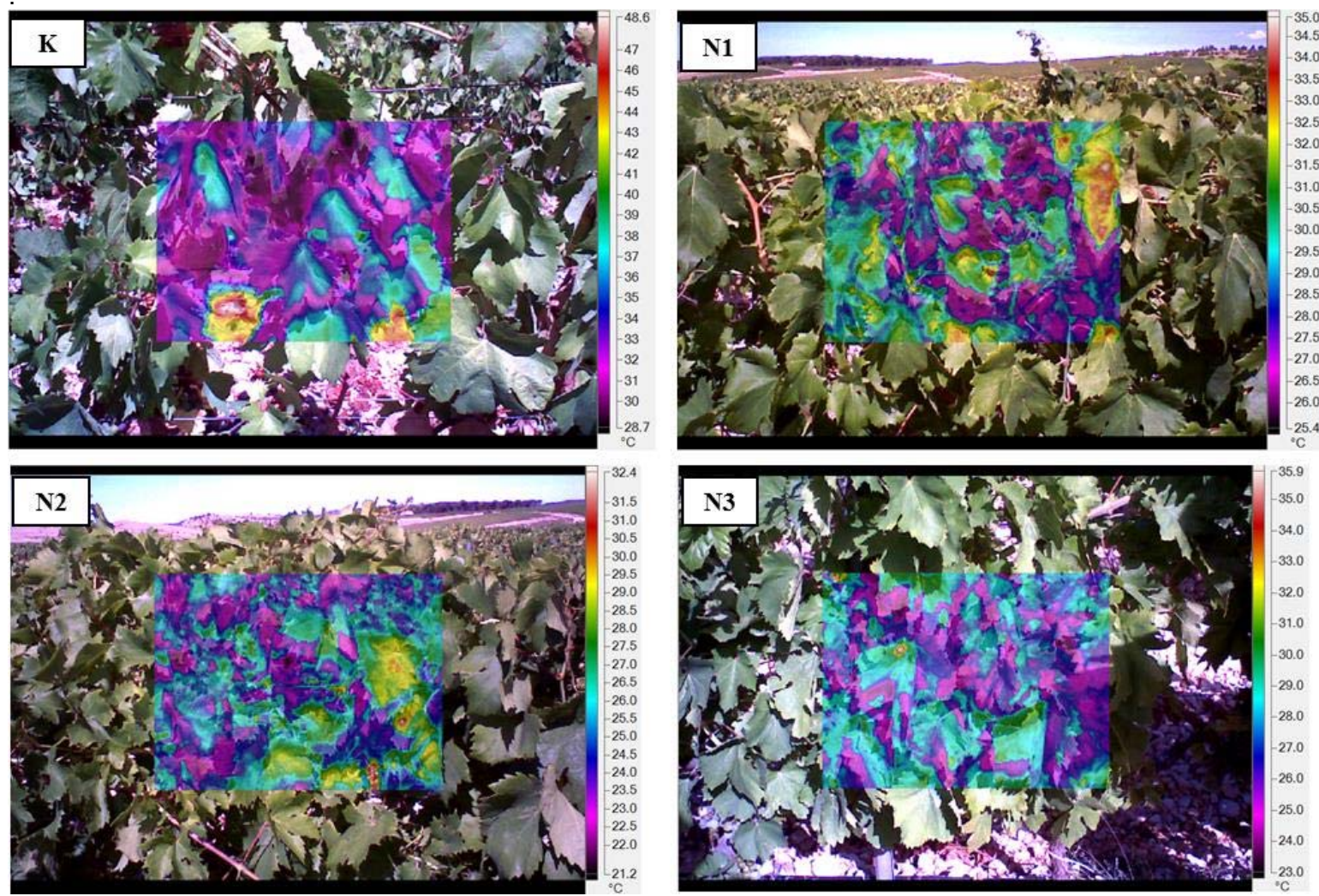

Fig. 2. Lateral photograph overlapped with thermal image of grapevine canopies in non-irrigated $(K)$ and irrigated in each water regime $\mathrm{N} 1, \mathrm{~N} 2, \mathrm{~N} 3$

As expected, there was variation in lateral canopy temperatures between irrigation regimes, with non-irrigated showing the highest temperature while the irrigation regime up to $100 \%$ of vine water demand showing the lowest temperature. Average canopy temperature in lateral canopies (figure 2) of non-irrigated grapevines $(\mathrm{K})$ was $32,1^{\circ} \mathrm{C}$, whereas average lateral canopy temperature of irrigated grapevines was $26,4^{\circ} \mathrm{C}(\mathrm{N} 3), 26,5^{\circ} \mathrm{C}(\mathrm{N} 2)$ and $28,0^{\circ} \mathrm{C}(\mathrm{N} 1)$, respectively. Higher coefficient of variation was found in the average canopy temperatures of non-irrigated grapevines (table 2) indicating more variation. For all irrigation regimes (N1, N2, N3) the lowest ranges of distribution of pixels 
temperatures (figure 3) were presented in canopy temperatures of grapevines irrigated up to $75 \% \mathrm{ET}_{\mathrm{c}}$ (N2). Negative kurtosis (table 2) was found for all irrigation regimes.
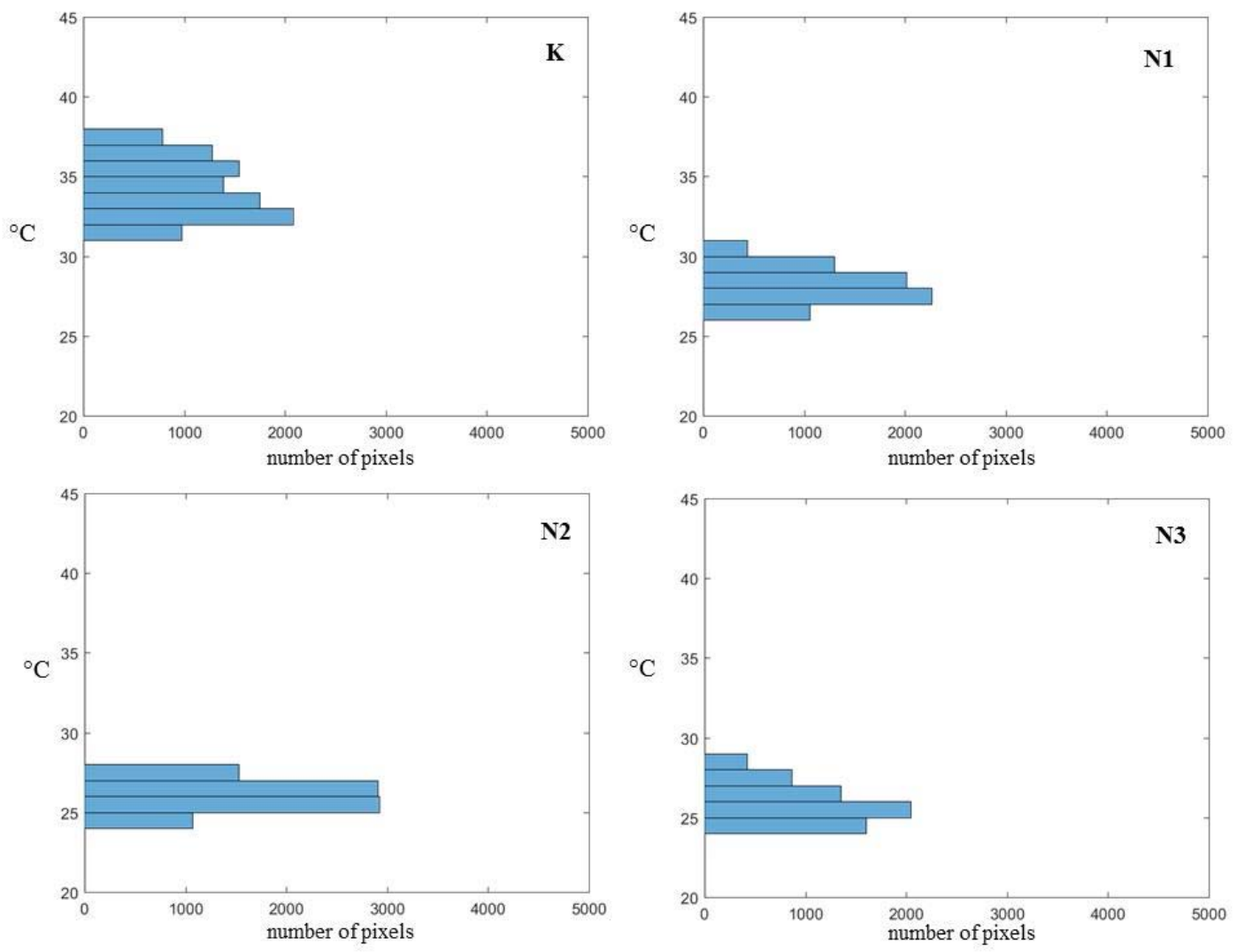

Fig. 3. Histograms of pixel temperatures of the grapevine canopies in non-irrigated $(K)$ and irrigated in each water regime $\mathrm{N} 1, \mathrm{~N} 2, \mathrm{~N} 3$

Table 2. Changes in average lateral canopy temperatures according to irrigation regimes

\begin{tabular}{|l|l|l|l|l|}
\hline \multirow{2}{*}{ Lateral canopy temperature } & \multicolumn{4}{l|}{ Irrigation regimes } \\
\cline { 2 - 5 } & $\mathrm{K}$ & $\mathrm{N} 1$ & $\mathrm{~N} 2$ & $\mathrm{~N} 3$ \\
\hline Average canopy temperature $\left({ }^{\circ} \mathrm{C}\right)$ & 32,1 & 28,0 & 26,5 & 26,4 \\
\hline Standard deviation & 2,280 & 0,973 & 1,183 & 0,743 \\
\hline Coefficient of variation $(\%)$ & 7,11 & 3,47 & 4,47 & 2,81 \\
\hline Skewness & $-0,84$ & 0,06 & 0,13 & $-0,39$ \\
\hline Kurtosis & $-0,306$ & $-1,321$ & $-1,687$ & $-0,034$ \\
\hline
\end{tabular}

Table 3 shows the effect of the different irrigation regime on the measurements of LWP. Average LWP exhibited values between $-1,7$ and $-1,0 \mathrm{MPa}$, indicating that non-irrigated $(\mathrm{K})$ vines showed severe water deficit $(<-1,4 \mathrm{MPa})$ and vines irrigated with up to $100 \% \mathrm{ET}_{c}$ (N3) showed weak water deficit (-0,9 MPa to $\left.-1,1 \mathrm{MPa}\right)$. Reasonably well differences in the vine water status is evident and its variability was much higher than that of average temperature canopy. Lowest coefficient of variation was found in LWP of grapevines irrigated with up to $100 \% \mathrm{ET}_{c}$ (N3) indicating less variation.

Distribution of pixel temperatures differ between irrigation regimes indicating that lateral canopy temperatures might be relevant indicator of grapevine water stress. Smaller variation of pixel temperatures within canopies of irrigated vines was found compared to canopies of non-irrigated grapevines (K). However, in stony soils considerable variability can occur in the infiltration and evaporation rate even between close points. Hence, the amount of plant-available water in such soil as well as their impact on vine physiology but their outcomes are generally affected by more than one agronomic soil characteristic. So, further research should focuse on the development of a new approach for soil and vegetation sensing, based on combining several sensing techniques to obtain a more comprehensive representation of the area under analysis. 
Table 3. Changes in LWP according to irrigation regimes

\begin{tabular}{|l|l|l|l|l|}
\hline \multirow{2}{*}{ LWP (MPa) } & \multicolumn{4}{l|}{ Irrigation regimes } \\
\cline { 2 - 5 } & $\mathrm{K}$ & $\mathrm{N} 1$ & $\mathrm{~N} 2$ & $\mathrm{~N} 3$ \\
\hline Average & $-1,7$ & $-1,3$ & $-1,1$ & $-1,0$ \\
\hline Standard deviation & 0,14 & 0,13 & 0,16 & 0,07 \\
\hline Coefficient of variation (\%) & 8,48 & 9,85 & 14,02 & 6,71 \\
\hline Skewness & 0,958 & 0,977 & 1,032 & 0,146 \\
\hline Kurtosis & 1,177 & $-0,140$ & 3,949 & $-1,060$ \\
\hline
\end{tabular}

\section{Conclusions}

The current study is a first attempt to apply the digital thermography in artificially created stony soil, in order to implement accurate and easy techniques for assessing and monitoring vine water status. The application of this technology and methodology for efficient irrigation managements in vineyards open new opportunities and challenges in future precision irrigation but should be verified in various experimental conditions. However, even these preliminary results demonstrate the potential of the digital thermography as useful tool for vineyard drought stress detection and precision irrigation.

\section{REFERENCES}

[1] Zovko, M., Žibrat, U., Knapič, M., Bubalo, M., Romić, M., Romić, D. Hyperspectral imagery as a supporting tool in precision irrigation of karst landscapes // Advances in Animal Biosciences: Precision Agriculture (ECPA) /Cledwyn, Thomas (ed.). Midlothian, Velika Britanija: Cambridge University Press, 2017. pp. 578-582 2017. https://doi.org/10.1017/S2040470017000991.

[2] C. Van Leeuwen, O. Tregoat, X. Chone, B. Bois, D. Pernet and J.-P. Gaudillere, "Vine water status is a key factor in grape ripening and vintage quality for red Bordeaux wine. How can it be assessed for vineyard management purposes?," J. Int. Sci. Vigne Vin, vol. 43, no. 3, pp. 121-134, 2009.

[3] L. E. Williams, "Irrigation of winegrapes in California," Practical Winery \\& Vineyard, vol. 23, pp. 42-55, 2001.

[4] Al-Yahyai, R., Schaffer, B. Davies, F. S., Munõz-Carpena, R. (2006). Characterization of soil-water retention of a very gravelly loam soil varied with determination method. Soil science Vol. 171, No. 2.

[5] PMS, "PMS Instruments Company: Pressure Chambers," 2017.

[6] Alchanatis V, Cohen Y, Cohen S, Moller M, Sprinstin M, Meron M, Tsipris J, Saranga Y, Sela E. "Evaluation of different approaches for estimating and mapping crop water status in cotton with thermal imaging". Precision Agriculture 11, 27-41, 2010. 